\title{
Classifying by learning disabled and nondisabled children: Use of overall similarity versus dimensional relations
}

\author{
THOMAS B. WARD \\ Texas A\&M University, College Station, Texas
}

(Steven M. Smith, Sponsor)

\begin{abstract}
Previous research indicates that learning disabled (LD) children perceive more holistically than do their nondisabled (nonLD) peers. The present study investigated whether or not the holistic perception of LD children is structured by the principle of overall similarity. LD and nonLD children in the second and fourth grades performed a restricted classification task (RCT) with four types of materials. The RCT allows classifications based on overall similarity or dimensional structure. The fourth-grade LD children were more likely than the fourth-grade nonLD children to use overall similarity in making their choices and were less likely than the fourth-grade nonLD children to use the component dimensions of the stimuli. Second-grade LD and nonLD children did not differ. The nonLD children shifted away from similarity choices toward dimensional choices with increasing age, whereas the LD children did not. The results are discussed in terms of their implications for school performance, selective attention, and category generalization.
\end{abstract}

Research on the perceptual and cognitive styles of learning disabled (LD) and nondisabled (nonLD) children indicates that LD children are impulsive and field-dependent relative to their nonLD peers (for a review, see Blackman \& Goldstein, 1982). Both types of cognitive style exhibited by LD children are consistent with a tendency to perceive the world in a global, holistic, or undifferentiated manner. There is evidence, for example, that impulsive and field-dependent individuals tend to process information holistically, whereas reflective and field-independent individuals process information more analytically (Ward, 1983, 1985; Zelniker \& Jeffrey, 1976)

Descriptions of the LD child's perception as holistic are reminiscent of earlier characterizations of the younger nonLD child's perception as being global, holistic, or undifferentiated (see, e.g., Gibson, 1969; Vurpillot, 1976; Werner, 1961). Although the precise meaning of the term holistic has not always been given, recent research in developmental psychology has sought to specify more precisely the nature of the young child's perception. In this effort, several investigators have made use of Garner's (1974) distinction between separable and integral perception (Shepp \& Swartz, 1976; Smith \& Kemler, 1977; Ward, 1980), and the present research was an attempt to

This project was funded by a grant from the Public Policy Resources Laboratory of Texas A\&M University. The author thanks the principals and teachers of the Southwood Valley, South Knoll, and College Hills elementary schools for their kind cooperation in this project. The author's mailing address is: Department of Psychology, Texas A\&M University, College Station, TX 77843-4235. apply the same ideas to the holistic perception of LD children.

According to Garner (1974), different stimulus dimensions interact or combine in different ways, and those differing interactions result in distinct perceptual experiences. Of most importance in the present context, some dimensions (e.g., hue and saturation) combine in such a way that they are perceived as unitary (i.e., holistic); these dimensions are referred to as integral. Other dimensions (e.g., the size and brightness of a geometric form) combine in such a way that they can be perceived as isolated or separate from one another (i.e., analytic); these dimensions are termed separable.

Recent studies have demonstrated that young children respond to separable dimensions as though they were integral (Shepp, Burns, \& McDonough, 1980; Shepp \& Swartz, 1976; Smith \& Kemler, 1977; Ward, 1980). Thus, it appears useful to characterize the young child's holistic perception as being similar to adults' perception of integral dimensions. ${ }^{1}$ This more precise characterization allows the theoretical framework surrounding the distinction between separable and integral perception to be brought to bear on our understanding of perceptual development.

The present study was designed to determine whether or not the LD child's holistic perception can also be more precisely characterized as integral. The task employed, called a restricted classification task (RCT), is commonly used in studies of integral and separable perception (see, e.g., Garner, 1974; Shepp et al., 1980; Smith \& Kemler, 1977; Ward, 1980, 1983) and makes use of the idea that integral perception is structured by overall similarity, whereas separable perception is structured by com- 
ponent dimensions. In the RCT, participants are presented with three items on each trial and are asked to select the two out of three that "go together best." The three items presented on any given trial are chosen from a larger set of items which vary along two dimensions. In each group of three, there are two items which are identical on one dimension and very different on the other dimension. These items are referred to as the dimension pair. In each group of three, there also are two items which differ slightly on both dimensions but are highly similar to one another in overall appearance. These are referred to as the similarity pair. The items comprising the third possible pairing are referred to as the haphazard pair and are neither identical on one dimension nor overall highly similar. Since haphazard responses occur infrequently, the task basically pits classifications on the basis of dimensional identity against those on the basis of overall similarity. A large number of dimensional responses is indicative of separable perception, and a large number of similarity responses is indicative of integral perception (Garner, 1974; Smith \& Kemler, 1977).

Second- and fourth-grade LD and nonLD children performed the RCT with four different types of simple visual stimuli: circles varying in size and in the angle of the radius within the circle (in degrees from vertical), lines of dots varying in length and density, squares varying in size and brightness, and patches of color varying in saturation and brightness. The materials were chosen to represent a wide range of separability from the readily analyzable circles to the highly integral color patches. Previous research has demonstrated that individuals of all ages perceive saturation and brightness as integral (e.g., Garner, 1974; Shepp \& Swartz, 1976). In contrast, the other three types of materials have evoked more integral responses from young children (5-year-olds) and more separable responses from older children and adults (Shepp et al., 1980; Smith \& Kemler, 1977; Ward, 1980). Thus, if the relatively holistic perception of LD children is integral in the same sense that younger children's holistic perception is integral, it can be predicted that LD children will give more integral (similarity) responses and fewer separable (dimensional) responses than will nonLD children of the same age to all materials except the integral saturation and brightness stimuli. On the other hand, since circle area and radius orientation are thought to be easily separated (see Shepp et al., 1980), it may be that all children will perceive them separably and that only the lines and squares will reveal differences between LD and nonLD children.

\section{METHOD}

\section{Participants}

The participants were second graders (mean age $=8$ years, 3 months) and fourth graders (mean age $=10$ years, 7 months) enrolled in the College Station Independent School District (CSISD). The second-grade group included $16 \mathrm{LD}$ and 24 nonLD children, and the fourth-grade group included 20 LD and 20 nonLD children. The LD children were chosen from those identified as learning disabled based on CSISD proce- dures, which involve assessment of performance on a battery of intelligence and achievement tests. Children achieving at least one standard deviation below their potential are considered to be learning disabled. Children exhibiting other difficulties, such as emotional disturbance and mental retardation, were excluded from the study. NonLD children who represented the best possible match with LD children in terms of age, IQ, and SES were identified by school personnel. ${ }^{2}$

\section{Stimuli}

The stimuli were chosen from four two-dimensional sets as follows. The circles were chosen from a set representing the 36 possible combinations of areas $4.5,6.4,9.0,12.8,18.8$., and $25.8 \mathrm{~cm}^{2}$, and radius orientations of $5^{\circ}, 35^{\circ}, 65^{\circ}, 95^{\circ}, 125^{\circ}$, and $155^{\circ}$ from vertical. The circles and their radii were drawn in black ink on white backgrounds. The radii always extended $8 \mathrm{~mm}$ in length from the center of each circle. Each triad of circles was arranged in a single horizontal row across the long axis of an $81 \frac{1}{2} \times 11$ in. white sheet of paper.

The lines of dots were chosen from the set of possible combinations of lengths $1,1.5,2,3,4,6$, and $8 \mathrm{~cm}$ and densities of 1.5-, 1-, .75-, $.50-, .25-$, and $.125-\mathrm{cm}$ interdot distance. The lines of a given triad were typed one above the other and centered on $3 \times 5$ in. white index cards.

For the squares, triads were chosen from the possible combinations of side lengths $2,2.5,3,4$, and $5 \mathrm{~cm}$ and brightnesses G4, G6, G10, G12, G14, and G16 (Colormatch values). The squares of each triad were depicted in a horizontal row on a sheet of white paper.

The color patches were cut from Munsell glossy color standards of chromas (saturation) 4, 6, 8, and 10, and values (brightness) 3, 4, 5, and 6 . The color patches for each triad were $3 / 4$-in. square and were arranged in a horizontal row on a white index card.

For each of the four sets of materials, eight distinct triads were constructed with half having one of the component dimensions as the dimensional response and half having the other component dimension as the dimensional response. Three versions of each triad were constructed so that each triad member could appear in each position on the sheet (card) and each response type (dimensional, similarity, and haphazard) could appear in each possible pairing of positions. This resulted in a total of 24 triad presentations for each set of materials.

\section{Procedure}

Children were tested individually in a small room in their school building. They were shown each triad individually and were asked to pick the two out of three items in each triad that went together best. They were given no feedback regarding the correctness of their answers. All children made classification decisions for all four sets of materials which resulted in 96 choices by each child.

Children made all 24 choices for one set of materials (e.g., circles), then all 24 choices for another set, and so on. Order of material presentation was counterbalanced across children in each group so that each set of materials occurred equally often in the first, second, third, and fourth presentation positions.

\section{RESULTS}

The proportion of dimensional responses given to each set of materials is depicted in Table 1, separately for the LD and nonLD second and fourth graders. Several important conclusions can be drawn from the data depicted in Table 1, and these conclusions are supported by the results of an analysis of variance conducted on the number of dimensional responses. The analysis included sex, group (LD vs. nonLD), and class (second vs. fourth grade) as between-subjects variables, and dimension type (circles, lines, squares, color patches) as a within-subject variable.

As depicted in Table 1, the nonLD children made more dimensional (separable) responses overall than did the LD children. Although the overall group differences are small, 
Table 1

Proportion of Dimensional (Separable) Responses Made by Second- and Fourth-Grade Learning Disabled and Nondisabled Children

\begin{tabular}{lcccc}
\hline & \multicolumn{4}{c}{ Class and Group } \\
\cline { 2 - 5 } & $\begin{array}{c}\text { Second } \\
\text { Type of Material }\end{array}$ & $\begin{array}{c}\text { Second } \\
\text { NonLD }\end{array}$ & $\begin{array}{c}\text { Fourth } \\
\text { LD }\end{array}$ & $\begin{array}{r}\text { Fourth } \\
\text { NonLD }\end{array}$ \\
\hline Saturation-Brightness & .12 & .09 & .10 & .06 \\
Length-Density & .27 & .26 & .25 & .37 \\
Size-Brightness & .36 & .41 & .41 & .50 \\
Area-Orientation & .41 & .45 & .46 & .47 \\
$\quad$ Mean & .29 & .31 & .31 & .35 \\
\hline
\end{tabular}

they are statistically reliable, as revealed by a significant group effect $[F(1,72)=6.51, p<.05]$. Perhaps more important than the small overall differences, inspection of Table 1 also reveals that the greatest difference between the groups occurred for the moderately separable dimensions of length and density and of size and brightness, as predicted, and that the differences were particularly large among fourth graders. Confirming these observations is the fact that the analysis of variance revealed a significant group $\times$ dimension type interaction $[F(3,216)$ $=3.52, p<.05]$ and a marginally significant group $\times$ class $\times$ dimension type interaction $[F(3,216)=2.42$, $p=.067$ ]. Subsequent comparisons revealed that the differences in dimensional responding between the $L D$ and nonLD children were significant only for fourth graders and only for the moderately separable size and brightness $[t(38)=3.04, p<.01]$ and length and density $[t(38)=$ $3.44, p<.01]$ materials. Since the group $\times$ class $\times$ dimension type interaction was only marginally significant, this evidence for a greater effect among fourth graders must be interpreted cautiously. However, further comparisons also revealed that the nonLD children showed increases in dimensional responding from Grade 2 to Grade $4[t(42)=2.88, p<.01]$, whereas the LD children did not $[t(34)=.80, p>.40]$. The increase in dimensional responding shown by nonLD children is consistent with previous developmental studies. The failure of LD children to show such a shift, combined with the finding of group differences only among fourth graders, indicates that LD children may be falling progressively behind their nondisabled peers in movement toward a more separable perceptual style with increasing age.

Analyses conducted on the number of similarity responses reveal a pattern complementary to that reported for dimensional responses. Of most interest, among the fourth graders, the LD children made significantly more similarity (integral) responses to the moderately separable length and density $[t(38)=3.36, p<.01]$ and size and brightness $[t(38)=2.55, p<.05]$ materials than did the nonLD children. In addition, it appears that the nonLD children show a decline in similarity responses from second to fourth grade $[t(42)=1.97, p<.05]$, whereas the LD children do not $[t(34)=.46, p>.65]$.

\section{DISCUSSION}

The most important finding of the present study is that learning disabled children perceive moderately separable stimuli as more integral than do their nondisabled peers of the same age. This difference is particularly strong among fourth graders. The results obtained in comparing the performance of LD and nonLD children are analogous to those obtained in comparing the performance of younger and older children (Shepp et al., 1980; Shepp \& Swartz, 1976; Smith \& Kemler, 1977; Ward, 1980).

The fact that there are similarities between the LD child's processing of separable materials and both the young child's processing of those materials and the adult's processing of integral materials can have implications for many areas of study. These include general school performance, selective attention, and category generalization.

Consider first the implications for the LD child's difficulty in school. In a general way, school can be thought of as an analytic event in the sense that we expect children to learn to break the world into details and components. If LD children tend to approach tasks in an integral, holistic fashion, then they are likely to have difficulty in the classroom situation.

In addition to being a possible cause of academic difficulty in LD children, the tendency of such children to perceive integrally may have implications for our understanding of results from selective attention studies. Since selective attention is extremely difficult when stimuli are perceived integrally (see Garner, 1974), it may be that the LD child's poor performance in selective attention tasks (see, e.g., McIntrye, Murray, \& Blackwell, 1981; Ross, 1976) is due to a greater tendency to perceive integrally rather than to a lack of ability in the process of selective attention per se.

The results of the present study may also have implications for our assessment of the LD child's ability to generalize from a category to a new instance of that category. For example, Smith (1979) showed that in contrast to theoretical predictions (see, e.g., Inhelder \& Piaget, 1964), even very young children are capable of generalizing to a new instance of a category as long as the category is defined by a rule that is consistent with the child's style of perceiving (i.e., overall similarity). Likewise, the most accurate assessment of the LD child's ability to generalize to new instances of a category might be obtained in tasks in which the categories are structured by overall similarity.

The results of the present study provide suggestive evidence for a new conceptualization of the LD child's more holistic perceptual style (i.e., that that style can be described as integral). Much research remains to be done in order to determine the extent to which the LD child's integral processing of separable materials mimics either the young child's integral processing or adults' processing of integral materials as described by Garner (1974). One advantage of adopting this new conceptualization as a working hypothesis is that the extensive theoretical framework surrounding the separable/integral distinction can be used to guide research efforts. Whether or not the hypothesis holds up well to future empirical tests, those tests will provide a considerable amount of information on the perceptual style of learning disabled children.

\section{REFERENCES}

Blackman, S., \& Goldstein, K. M. (1982). Cognitive styles and learning disabilities. Journal of Learning Disabilities, 15, 106-115.

GARNER, W. R. (1974). The processing of information and structure. Potomac, MD: Erlbaum.

GiBson, E. J. (1969). Principles of perceptual learning and development. New York: Appleton-Century-Crofts.

GiBSON, E. J. (1983). Commentary on the development of perception and cognition. In T. J. Tighe \& B. E. Shepp (Eds.), Perception, cognition and development: Interactional analyses. Hillsdale, $\mathrm{NJ}$ : Erlbaum.

INHelder, B., \& PiAget, J. (1964). The early growth of logic in the child. New York: Norton.

McIntyre, C. W., Murray, M. E., \& Blackwell, S. L. (1981). 
Visual search in learning disabled and hyperactive boys. Journal of Learning Disabilities, 14, 156-158.

Ross, A. O. (1976). Psychological aspects of learning disabilities and reading disorders. New York: McGraw-Hill.

Shepp, B. E., Burns, B., \& McDonough, D. (1980). The relation of stimulus structure to perceptual and cognitive development: Further tests of a separability hypothesis. In F. Wilkening, J. Becker, \& T. Trabasso (Eds.), Information integration by children. Hillsdale, NJ: Erlbaum.

Shepp, B. E., \& SwarTz, K. B. (1976). Selective attention and the processing of integral and nonintegral dimensions: A developmental study. Journal of Experimental Child Psychology, 22, 73-85.

SMITH, L. B. (1979). Perceptual development and category generalization. Child Development, 50, 705-715.

Smith, L. B., \& KemLER, D. G. (1977). Developmental trends in free classification: Evidence for a new conceptualization of perceptual development. Journal of Experimental Child Psychology, 24, 279-298.

VuRPILLOT, E. (1976). The visual world of the child. New York: International Universities Press.

WARD, T. B. (1980). Separable and integral responding by children and adults to the dimensions of length and density. Child Development, 51, 676-684.

WARD, T. B. (1983). Response tempo and separable-integral responding: Evidence for an integral-to-separable processing sequence in visual perception. Journal of Experimental Psychology: Human Perception \& Performance, 9, 103-112.
WARD, T. B. (1985). Individual differences in processing stimulus dimensions: Relation to selective processing abilities. Perception \& Psychophysics, 37, 471-482.

WERNER, H. (1961). Comparative psychology of mental development. New York: Scientific Editions.

ZELNIKER, T., \& JEFFREY, W. E. (1976). Reflective and impulsive children: Strategies of information processing underlying differences in problem solving. Monographs of the Society for Research in Child Development, 41(5, Serial No. 168).

\section{NOTES}

1. Strictly speaking, all perception can be considered holistic (see, e.g., Gibson, 1983). However, based on young children's performance in various tasks, young children appear less likely than adults to decompose their internal holistic representations of stimuli into details or components. Thus, for ease of reference, the perception of young children will be referred to as more holistic and less analytic than that of older children or adults.

2. This approach was adopted because CSISD policies prohibit the release of test score information.

(Manuscript received for publication October 26, 1985.) 